Article

\title{
Third-Person Perceptions and Calls for Censorship of Flat Earth Videos on YouTube
}

\author{
Asheley R. Landrum * and Alex Olshansky \\ College of Media and Communication, Texas Tech University, Lubbock, TX 79409, USA; E-Mails: a.landrum@ttu.edu (A.R.L.), \\ alex.olshansky@ttu.edu (A.O.) \\ * Corresponding author
}

Submitted: 30 January 2020 | Accepted: 22 March 2020 | Published: 26 June 2020

\begin{abstract}
Calls for censorship have been made in response to the proliferation of flat Earth videos on YouTube, but these videos are likely convincing to very few. Instead, people may worry these videos are brainwashing others. That individuals believe other people will be more influenced by media messages than themselves is called third-person perception (TPP), and the consequences from those perceptions, such as calls for censorship, are called third-person effects (TPE). Here, we conduct three studies that examine the flat Earth phenomenon using TPP and TPE as a theoretical framework. We first measured participants' own perceptions of the convincingness of flat Earth arguments presented in YouTube videos and compared these to participants' perceptions of how convincing others might find the arguments. Instead of merely looking at ratings of one's self vs. a general 'other,' however, we asked people to consider a variety of identity groups who differ based on political party, religiosity, educational attainment, and area of residence (e.g., rural, urban). We found that participants' religiosity and political party were the strongest predictors of TPP across the different identity groups. In our second and third pre-registered studies, we found support for our first study's conclusions, and we found mixed evidence for whether TPP predict support for censoring YouTube among the public.
\end{abstract}

\section{Keywords}

censorship; conspiracy theories; fake news; flat Earth; third-person effects; third-person perceptions; YouTube

\section{Issue}

This article is part of the issue "Health and Science Controversies in the Digital World: News, Mis/Disinformation and Public Engagement" edited by An Nguyen (Bournemouth University, UK) and Daniel Catalan (University Carlos III of Madrid, Spain).

(C) 2020 by the authors; licensee Cogitatio (Lisbon, Portugal). This article is licensed under a Creative Commons Attribution 4.0 International License (CC BY).

\section{Introduction}

Flat Earth ideology resurfaced from obscurity due to a proliferation of misinformation on YouTube (Landrum \& Olshansky, 2019; Paolillo, 2018). True believers, though, are rare. Despite the videos' presence on YouTube and the widespread media coverage the movement has received, a 2018 poll reports only $5 \%$ of the U.S. public say they doubt the true shape of Earth, and only $2 \%$ are certain that Earth is flat (YouGov, 2018a). A greater proportion of the U.S. public, for example, believe they have seen a ghost (15\%; YouGov, 2018b).
While most do not find the arguments made in flat Earth videos persuasive, at least at first exposure (Landrum, Olshansky, \& Richards, 2019), a barrage of news articles highlight calls for YouTube to crack down on the spread of misinformation; and YouTube has responded by updating its recommendation algorithm (e.g., Binder, 2019; YouTube, 2019). People's strong negative reactions are not likely due to fears that they, themselves, will be persuaded, but fears that the videos will brainwash others (Scott, 2019). Indeed, research finds that individuals often overestimate the effects media have on others (and generally underestimate the effects 
on themselves), a phenomenon called third-person perception (TPP; Gunther, 1995; Perloff, 1993, 2009; Salwen, 1998). TPP, then, is thought to lead to certain attitudes and/or actions, such as support for censorship; and this is called third-person effects (TPE; Davison, 1983; Gunther, 1991; Perloff, 1993).

In three studies, we examine the flat Earth YouTube phenomenon using TPP and TPE as a theoretical framework. In these studies, we asked participants how convincing they found flat Earth arguments from YouTube videos and compared this to their expectations for how convincing others might find the arguments. Instead of merely looking at ratings of one's self vs. a general 'other,' however, we ask about a variety of groups who differ based on political party, religiosity, educational attainment, and area of residence (rural, urban).

We had two aims for this research. First, we aimed to determine which identity groups our participants believe are more susceptible than themselves to the arguments presented in flat Earth videos, and whether these TPP are conditional on participants' own characteristics (e.g., political party, religiosity). Second, we aimed to determine the extent to which TPP predict support for censoring YouTube compared to other participant characteristics (e.g., political party, conspiracy mentality, YouTube use).

\subsection{TPP vs. TPE}

The expectation that others will be more influenced by media messages than oneself is referred to as TPP, whereas the attitudes or behaviors that stem from TPP, such as calling for censorship of those messages, are referred to as TPE (Davison, 1983). The TPP and TPE model takes a meta-perspective, looking not at the direct effects of media but at the effects that result from people's beliefs about media effects (Perloff, 2009).

\subsection{TPP of Conspiracy Theories}

Although TPP and TPE are well researched in areas such as advertisements (e.g., Huh, Delorme, \& Reid, 2004), violent media (e.g., Hoffner \& Buchanan, 2002; Innes \& Zeitz, 1988), and pornography (e.g., Gunther, 1995; Rojas, Shah, \& Faber, 1996; Zhao \& Cai, 2008), very little work examines TPP of conspiracy theories.

Douglas and Sutton conducted one such study with a U.K. student sample in the 2000s, asking about conspiracy theories surrounding the death of Princess Diana (Douglas \& Sutton, 2008). Besides asking participants how much they and others would agree with the conspiracy statements (i.e., current selves, current others), they also asked participants to speculate how much they and others would have agreed with the statements prior to having read the material (i.e., retrospective selves, retrospective others). Inconsistent with prior work on TPP, collapsed across current and retrospective ratings, participants did not expect others to agree with the conspiracy statements more than themselves. However, par- ticipants did expect others to exhibit greater attitude change (Douglas \& Sutton, 2008).

Our study differs from Douglas and Sutton (2008) in a number of ways, but a central difference is who the 'others' are. Whereas Douglas and Sutton asked participants to rate their own classmates-a group of 'others' whom the participants might have seen as similar to themselves, we asked about several identity groups that could range from very similar to very different from our participants. We expected that participants' TPP would vary based on perceived social distance (the 'social distance corollary,' Cohen, Mutz, Price, \& Gunther, 1988).

\subsection{Social Distance and TPP}

Social distance has been at the center of much research on TPP (e.g., Cohen et al., 1988; Eveland, Nathanson, Detenber, \& McLeod, 1999; Paek, 2009; Shen \& Huggins, 2013). Cohen et al. (1988), for example, demonstrated that TPE magnify as the 'other' group becomes more abstract. These researchers asked Stanford University undergraduates to consider the effects of negative political ads on themselves, on other Stanford students, on other Californians, and on public opinion at large (Cohen et al., 1988). As social distances between an individual and 'others' increase, the individuals' perceptions of the others become more abstract; and the more abstract others are to us, the greater we believe they are susceptible to negative media effects (Meirick, 2004).

Social distance can also be conceptualized as psychological distance, or the degree of (dis)similarity between the self and the other (Perloff, 1993), with the resulting perception exemplifying in-group/out-group bias (e.g., David, Morrison, Johnson, \& Ross, 2002; Gardikiotis, 2008; Lo \& Wei, 2002; Wei, Chia, \& Lo, 2011). Jang and Kim (2018), for example, found strong TPP based on political party affiliation: Republicans believed Democratic voters would be more susceptible to so-called 'fake news,' whereas Democrats believed Republican voters would be more susceptible.

\subsection{Current Article}

Three studies examine our research aims. The first study explores associations between YouTube users' individual characteristics (e.g., their political party affiliation and religiosity) and their expectations for how convincing other people would find YouTube clips arguing Earth is flat. These 'other people' included people described as Democrats, Republicans, biblical literalists, atheists, rural dwellers, urban dwellers, those who did not go to college, and those who attended graduate school. The second study examines the relationships between YouTube users' individual characteristics, third-person ratings, and their support for censoring such content on YouTube. The third study attempts to replicate study 2 with a larger and more nationally representative sample that was not limited to YouTube users. 


\section{Study 1}

\subsection{Participants}

We recruited 397 U.S. participants who regularly use YouTube via TurkPrime, a service of Amazon's Mechanical Turk. We requested a naïve sample: The top $2 \%$ of most active MTurkers were not eligible for our study. Overall, $57 \%$ of the participants were female, and racial/ethnic breakdowns were as follows: $76 \%$ White, 11\% Black/African American, 7\% Hispanic/Latino, 6\% Asian, and $2 \%$ other. The average age of participants was 38.39 years (median $=36, S D=12.29$ ). $11 \%$ completed only high school, $38 \%$ attended some college, $35 \%$ received some degree from college, and $16 \%$ completed graduate school. About $43 \%$ identify as Democrat, $37 \%$ identify as independent, and only $21 \%$ identify as Republican.

MTurk samples tend to be higher educated and hold more politically liberal views compared to U.S. nationally representative populations, and this was true of our sample. They also tend to have a higher number of atheists and agnostics compared to the U.S. population (Burnham, Le, \& Piedmont, 2018), which appears to be the case for our sample. Over $41 \%$ of our study 1 participants said that they are not religious and never pray.

\subsection{Study Design and Procedures}

Data for study 1 were collected as part of a study examining susceptibility to flat Earth arguments on YouTube (see Landrum et al., 2019). Participants were randomly assigned to one of four conditions that determined which 30-second video clip they saw. Participants then answered questions about the video, including how convincing they and others were likely to find it. Lastly, participants answered standard demographic questions which were followed by a fact check statement explaining why the argument was misinformative. Participants received \$2 upon survey completion.

\subsection{Stimulus Materials}

As stated above, participants were randomly assigned into one of four conditions which presented different flat Earth arguments: (1) a science-based argument, (2) a conspiracy-based argument, (3) a religious-based argument, or (4) a sensory-based argument. See the Supplementary File for descriptions of the videos. The clips were cut from a YouTube video well known within the flat Earth community, 200 Proofs the Earth Is Not a Spinning Ball (Dubay, 2018). The following text preceded each of the videos: "In the video, 200 Proofs the Earth Is Flat the narrator makes the following argument." A transcription of the narration and the embedded video followed.

\subsection{Measures}

Only the measures used for this study are described here. For more information, see the Supplementary File and our project page at https://osf.io/h92y5.

\subsubsection{Convincingness}

After watching the video, participants were reminded of the argument made and were asked to report how convincing they found it using a slider scale ranging from 0 (not convincing) to 100 (extremely convincing). Later, participants were asked to rate how convincing they think other types of people might find the video using the same scale. These other groups were described as follows: Republicans, Democrats, people who think the Bible should be interpreted literally, people who do not believe God exists (atheists), people who live in rural areas (country), people who live in urban areas (cities), people who did not go to college, and people who attended graduate school.

\subsubsection{TPP Scores}

The dependent variable for this study was the difference in perceived susceptibility (i.e., TPP score), which was obtained by subtracting one's own rating of the argument's convincingness from one's expectations of how convincing each of the other identity groups would find the argument (e.g., TPP = Other group - Self rating; see Jang \& Kim, 2018; Wei et al., 2011). Therefore, TPP scores could range from +100 (indicating that the participant thinks the 'other' would be completely convinced whereas the participant is not at all convinced) to -100 (indicating that the participant is completely convinced and thinks that the other would not be convinced at all) for each of the eight different identity groups (e.g., TPP_rural = rating for people who live in rural areas - rating for the 'self'; TPP_biblit = rating for people who believe the Bible should be interpreted literally - rating for the 'self'; Figure 1).

\subsubsection{Religiosity}

Participants were asked two questions to gauge their religiosity: (1) how much guidance does your faith, religion, or spirituality provide in your day-to-day life on a 6-point scale (not religious to a great deal), and (2) do you pray, and if so, how often, on a 5-point scale (I do not pray to at least daily). These two items were centered and scaled before being averaged together and rescaled; religiosity scores ranged from -1.02 to $1.51(M=0, S D=1$, Median $=-0.19$ ).

\subsubsection{Political Party Affiliation}

Political party affiliation was measured with 6 categories: strong Democrat $(n=58)$, Democrat $(n=106)$, 


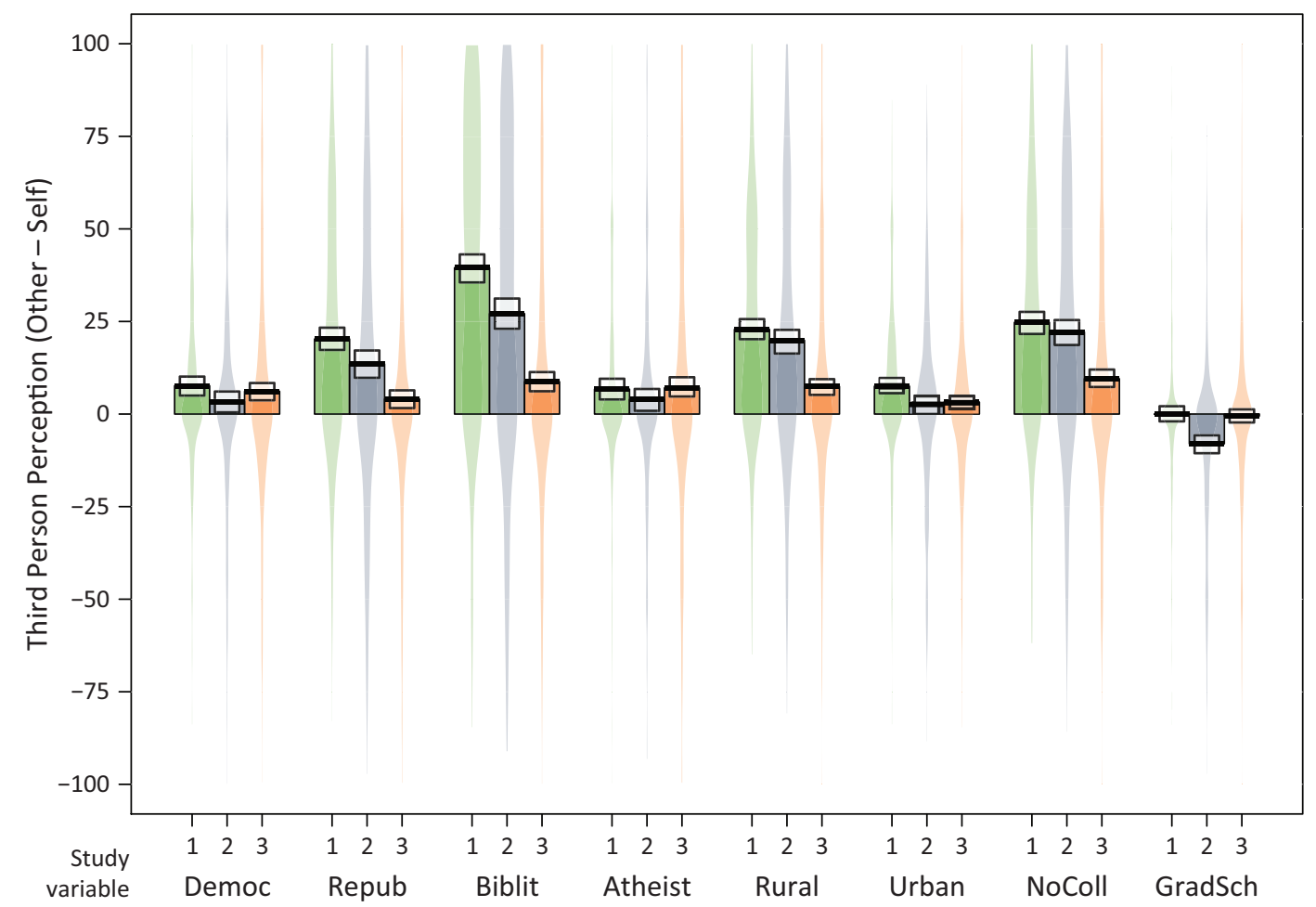

Figure 1. TPP scores for each identity group across the three studies.

Independent ( $\mathrm{n}=142)$, Republican $(\mathrm{n}=60)$, and strong Republican ( $n=20$ ), with an additional option of 'I choose not to answer' $(n=11)$. To reduce the number of comparison groups, strong Democrat and Democrat were combined into one response level, 'Democrat' ( $n=164$ ), and strong Republican and Republican were combined into one response level, 'Republican' $(n=80)$. Independent was kept as its own response level, and the 11 people who said they prefer not to answer were coded as missing. This variable was treated as categorical with Democrat as the referent in all analyses.

\subsubsection{Conspiracy Mentality}

Conspiracy mentality was measured using the 5-item generalized conspiracy mentality scale by Bruder, Haffke, Neave, Nouripanah, and Imhoff (2013). Participants were shown each statement, such as 'many important things happen in the world, which the public is never informed about,' and asked whether the statement is (1) definitely false to (4) definitely true. The five items perform well as a scale, predict belief in specific conspiracy theories (see project page), and have acceptable interitem reliability (Cronbach's alpha $=.75,95 \% \mathrm{CI} .72, .79]$ ). Participants scores on the conspiracy mentality scale were approximately normally distributed $(M=2.79$, Median $=2.8, S D=0.52$ ).

\subsubsection{Demographics}

We also asked a series of demographic questions including participants' age, gender, whether they live in rural
(23\%), urban $(26 \%)$, or suburban $(52 \%)$ areas, level of education, and race/ethnicity. The descriptives for these variables are reported in Section 2.1.

\subsection{Results}

\subsubsection{Rating the 'Self' vs. Rating the 'Other'}

First, we ask whether participants rate others as more convinced by the flat Earth videos than themselves. To examine this, we conducted a within-subjects ANOVA to test for a difference based on group rated, $F(8,3160)=149.9, p<.001$. Then, we conducted planned contrasts, comparing participants' ratings of how convincing they thought each of the identity groups would find the video compared to how convincing they found it. Study 1 participants reported that each identity group would be more convinced by the video than themselves, except when rating those who attended graduate school (see Table 1).

\subsubsection{Predicting TPP Scores}

Next, we aimed to determine whether participants' own characteristics (e.g., political party, religiosity) predicted their TPP for the different identity groups. To examine this, we conducted regression analyses predicting TPP scores from condition (video watched) and participants' political affiliation, religiosity, conspiracy mentality, income, gender, age, area of residence (rural, suburban, urban), and education level (see Table 2). To determine the relative importance of the predictors, we conducted 
Table 1. Planned comparisons between 'self' and 'other' identity groups for how convincing each will find the flat Earth video across the three studies.

\begin{tabular}{lcccccc}
\hline & \multicolumn{2}{c}{ Study 1 } & \multicolumn{2}{c}{ Study 2 } & \multicolumn{2}{c}{ Study 3 } \\
& Estimate & Cohen's $d$ & Estimate & Cohen's d & Estimate & Cohen's $d$ \\
\hline Self vs. Democrats & $7.63^{* * *}$ & 0.35 & 3.31 & 0.11 & $5.90^{* * *}$ & 0.19 \\
Self vs. Republicans & $20.26^{* * *}$ & 0.63 & $13.43^{* * *}$ & 0.35 & $3.76^{*}$ & 0.11 \\
Self vs. Bib literalists & $39.51^{* * *}$ & 1.00 & $26.99^{* * *}$ & 0.62 & $8.52^{* * *}$ & 0.23 \\
Self vs. Atheists & $6.72^{* * *}$ & 0.25 & $3.88^{\top}$ & 0.13 & $7.04^{* * *}$ & 0.19 \\
Self vs. Rural & $22.87^{* * *}$ & 0.77 & $19.77^{* * *}$ & 0.58 & $7.34^{* * *}$ & 0.24 \\
Self vs. Urban & $7.51^{* * *}$ & 0.34 & 2.72 & 0.11 & $3.17^{*}$ & 0.12 \\
Self vs. No College & $24.74^{* * *}$ & 0.82 & $22.03^{* * *}$ & 0.63 & $9.37^{* * *}$ & 0.28 \\
Self vs. Grad School & -0.03 & 0.00 & $-8.07^{* * *}$ & -0.32 & -0.67 & 0.02 \\
\hline
\end{tabular}

Notes: ${ }^{\top} p<.10,{ }^{*} p<.05,{ }^{* *} p<.01,{ }^{* * *} p<.001$.

Img tests (Grömping, 2006; Lindeman, Merenda, \& Gold, 1980), which partitions $R^{2}$ by averaging sequential sums of squares (Type I) across all orderings of predictors.

When predicting TPP, where the 'other' is described as a Democrat or Republican, participants' own religiosity and political affiliation were the strongest influencers. Among our participants, the greater one's religiosity, the less they believe Republicans will be more convinced than themselves by flat Earth videos ( $b=-6.08, p<.001)$-that is, the TPP score for Republicans decreases with increasing religiosity. On the other hand, greater religiosity marginally predicts believing that Democrats will be more convinced than themselves by flat Earth videos ( $b=2.86, p=.049)$-that is, the TPP score for Democrats slightly increases with increasing religiosity (see Figure 2 ).

Participants' own political affiliation also influenced TPP of Democrats and Republicans. Independents expected larger gaps between Democrats and themselves (that is, a TPP score greater than 0; $M_{\text {TPP Democ }}=12.83$, $S D=25.76)$ and between Republicans and themselves $\left(M_{\text {TPP Repub }}=19.99, S D=30.86\right)$. Republican participants, reasonably, expected smaller gaps between Republicans and themselves (that is, a TPP score closer to $0 ; M_{\text {TPP Repub }}=3.62, S D=33.13$ ) than Democrat participants expected when rating Republicans $\left(M_{\text {TPP Repub }}=29.76, S D=32.94\right)$. Notably, however, Repüblican participants and Democrat participants did not vary significantly when rating Democrats (Republicans rating Democrats: $M_{\text {TPP Democ }}=9.91, S D=33.13$; Democrats rating Democrats: $\left.M_{\text {TPP_Democ }}=3.05, S D=17.00\right)$.

When predicting TPP where the 'other' is described as living in urban or rural areas, participants' own political party affiliation was the strongest influencer. Most notably, Republicans expected smaller gaps-TPP scores closer to 0-between rural dwellers and themselves $\left(M_{\text {TPP_Rural }}=7.58, S D=26.0\right)$ than Democrats expected $\left(M_{\text {TPP_Rural }}=29.7, S D=29.5\right.$, $p<.001)$. Furthermore, independents expected larger differences between themselves and urban dwellers $\left(M_{\text {TPP Urban }}=12.0, S D=21.99\right)$ than Democrats ex- pected $\left(M_{\text {TPP_Urban }}=6.19, S D=19.32 ; p=.013\right)$. However, Republicans' expectations ( $M_{\text {TPP_Urban }}=4.38$, $S D=24.22)$ did not significantly differ from Democrats' expectations ( $p=.609)$

There was also an influence of conspiracy mentality: People with greater conspiracy mentality expected smaller gaps between rural dwellers and themselves than those with lower conspiracy mentality expected ( $b=-6.59, p=.033)$.

More factors significantly predicted TPP where the 'other' is described as a biblical literalist, and the strongest predictors were the participant's religiosity and political party, as well as whether the participant saw the religious appeal. Understandably, participants who saw the clip appealing to scripture as evidence of a flat Earth expected much larger gaps between biblical literalists and themselves $\left(M_{\text {TPP Biblit }}=61.17\right.$, $S D=34.42$ ) than people who saw the conspiracy appeal $\left(M_{\text {TPP_Biblit }}=29.04, S D=36.24, p<.001\right.$; see Table 2$)$.

Moreover, participants' religiosity played a significant role when rating atheists and biblical literalists. Greater religiosity predicted smaller gaps between participants' ratings of themselves and biblical literalists $(b=-10.55, p<.001)$ and greater gaps between themselves and atheists $(b=5.52, p<.001)$.

Participants' political affiliations also influenced their ratings of biblical literalists. Republicans expected smaller gaps between biblical literalists and themselves $\left(M_{\text {TPP_Biblit }}=19.09, S D=37.95\right)$ than Democrats expected $\left(M_{\text {TPP_Biblit }}=51.74, S D=37.5, p<.001\right)$. Independents also expected smaller gaps between biblical literalists and themselves $\left(M_{\text {TPP Biblit }}=38.84\right.$, $S D=37.67)$ than Democrats expected $\left(p^{-}=.010\right)$.

When predicting TPP where the 'other' did not attend college, participant's own political affiliation was the only significant influencer. Republicans expected smaller gaps between themselves and people who did not attend college $\left(M_{\text {TPP_NoCollege }}=10.91, \mathrm{SD}=28.09\right.$ ) than Democrats expected ( $M_{\text {TPP NoCollege }}=30.04$, $S D=30.13 ; b=-15.61, \mathrm{p}<.001)$. Moreover, no factors were significant when predicting TPP scores for those who attended graduate school. However, as noted ear- 
Table 2. GLM analyses for each identity group. Non-standardized regression coefficients are shown.

\begin{tabular}{|c|c|c|c|c|c|c|c|c|}
\hline & \multicolumn{8}{|c|}{ Characteristic defining the 'other' } \\
\hline & \multicolumn{2}{|c|}{ Political identity } & \multicolumn{2}{|c|}{ Area of residence } & \multicolumn{2}{|c|}{ Religiosity } & \multicolumn{2}{|c|}{ Education } \\
\hline & Dem & Repub & Urban & Rural & Atheist & Biblit & Grad & No College \\
\hline \multicolumn{9}{|c|}{ Condition (ref = Conspiracy appeal) } \\
\hline Religious & 3.64 & 6.37 & 0.63 & 3.70 & -4.59 & $31.60 * * *$ & 1.51 & 0.83 \\
\hline Science & 1.85 & 5.82 & 1.42 & 2.76 & -3.34 & 7.05 & -1.59 & 3.34 \\
\hline Sensory 1 & 1.96 & 0.42 & 4.79 & 1.35 & -2.94 & -0.09 & 4.00 & 2.15 \\
\hline Sensory 2 & 3.12 & 2.60 & 3.95 & 3.89 & -1.02 & -0.25 & 0.55 & 1.46 \\
\hline \multicolumn{9}{|c|}{ Participant Characteristics } \\
\hline \multicolumn{9}{|c|}{ Political Party (ref = Democrat) } \\
\hline Independent & $9.47 * *$ & $-6.16^{\top}$ & $6.52^{*}$ & -0.88 & 1.81 & $-10.64 *$ & 3.06 & 0.61 \\
\hline Republican & 4.07 & $-18.81^{* * *}$ & -1.64 & $-17.59 * * *$ & 0.28 & $-23.74 * * *$ & 0.76 & $-15.61 * * *$ \\
\hline Religiosity & $2.86^{*}$ & $-6.08 * * *$ & 0.65 & -2.43 & $6.40 * * *$ & $-11.39 * * *$ & 0.73 & -1.54 \\
\hline Conspiracy Mentality & -4.28 & $-5.38^{\top}$ & $-4.37^{\top}$ & $-6.59 *$ & -3.87 & -0.33 & -0.82 & -4.63 \\
\hline Income & -0.80 & -0.65 & -0.16 & -0.08 & -0.64 & -0.19 & -0.53 & 0.59 \\
\hline Gender & -2.10 & 0.70 & -2.54 & 2.35 & $-6.44^{*}$ & 1.74 & -0.35 & 3.30 \\
\hline Age & -0.12 & -0.03 & -0.08 & -0.15 & -0.04 & $0.33^{*}$ & 0.05 & -0.14 \\
\hline \multicolumn{9}{|l|}{ Area (ref = Urban) } \\
\hline Rural & $6.65^{\top}$ & 0.84 & $6.18^{\top}$ & -5.10 & 0.31 & 3.13 & -0.18 & -0.53 \\
\hline Suburban & -1.20 & -0.14 & 1.23 & -0.65 & -1.26 & 2.85 & -3.90 & -0.37 \\
\hline Education & 0.50 & 3.03 & 0.57 & 1.26 & -0.46 & 1.23 & -0.46 & $2.52^{\top}$ \\
\hline
\end{tabular}

Notes: ${ }^{\top} p<.10,{ }^{*} p<.05,{ }^{* *} p<.01,{ }^{* * *} p<.001$.

lier, this was the one group participants rated as no more likely to be convinced than themselves (see Figure 1).

\subsection{Discussion}

Study 1 was exploratory, aiming to examine which identity groups YouTube users believe are more susceptible than themselves to the arguments presented in flat Earth videos and whether these beliefs are conditional on participants' own characteristics (aim 1). Supporting

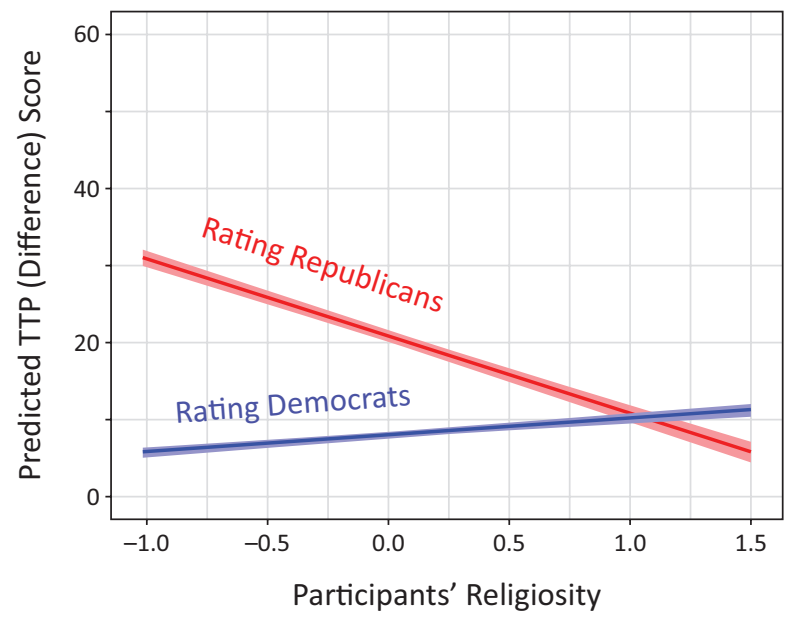

prior TPP work, we found that participants exhibited a 'self'-'other' bias, believing that the 'other' groups (with the exception of those who attended graduate school) would be more convinced by flat Earth videos than themselves. Participants believed biblical literalists, in particular, would be the most susceptible to flat Earth arguments in YouTube videos, especially when those arguments appeal to religious texts. In addition to biblical literalists, participants also expected people who did not go to college, people who live in rural areas, and

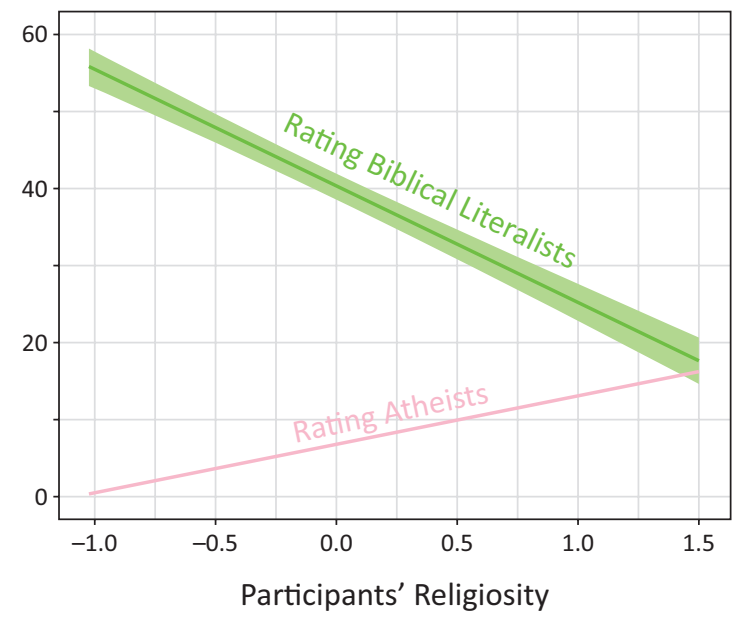

Figure 2. Predicted TPP scores ('other' minus 'self,' i.e., difference score) when rating how much more convincing Democrats and Republicans will find the flat Earth videos compared to oneself, and how this predicted difference score varies based on the participants' religiosity. 
people who vote Republican to be more susceptible to flat Earth videos. Notably, these TPP were predicted by participants' own religiosity and political affiliation. The strongest biases were expressed by those with lower religiosity. These non-religious individuals may have been more prevalent in our sample as we recruited participants from MTurk.

\section{Studies 2 and 3}

Studies 2 and 3 aimed to replicate the findings from study 1 that (1) supported prior literature by elucidating a 'self'-'other' bias (here, in perceived susceptibility to flat Earth YouTube videos), (2) suggested that respondents believe biblical literalists would be the most susceptible to flat Earth videos, and (3) showed that participants' TPP were primarily driven by their own (lack of) religiosity and their political party affiliations (aim 1). Moreover, studies 2 and 3 aimed to examine the extent to which perceptions of social distance predict TPP (aim 1) and the extent to which TPP predict support for censoring YouTube (aim 2). Whereas study 2 included a participant sample similar to study 1 (YouTube users recruited from MTurk), study 3 included a larger and more diverse participant sample, recruited by Qualtrics Research Services to match census, and not restricted based on YouTube use (as YouTube users may be less likely to want to censor the platform).

\subsection{Study 2 Participants}

We recruited 404 U.S. participants, who regularly use YouTube, in the summer of 2019 via TurkPrime. Overall, $53 \%$ of the participants were female, and racial/ethnic breakdowns were as follows: $72 \%$ White, 8\% Black/African American, 2\% Hispanic/Latino, 6\% Asian, and $1 \%$ Other. The average age of participants in this sample was 35.82 years (median $=33, S D=11.63$ ). As with study 1 , this sample was highly educated: $12 \%$ only completed high school, $33 \%$ attended some college, $38 \%$ received a four-year college degree, and $15 \%$ stated that they completed graduate school. This sample was also predominantly liberal leaning: about $54 \%$ report voting Democrat, $10 \%$ report voting independent, $21 \%$ report voting Republican, and $15 \%$ report not voting.

\subsection{Study 3 Participants}

A sample of 1,005 participants were recruited in winter 2019 by Qualtrics Research Services to match U.S. census on gender, age, education, household income, region, and race/ethnicity. The final sample was $56 \%$ female, and racial/ethnic breakdowns were as follows: $61 \%$ White, 14\% Black/African American, 4.5\% Hispanic/Latino, 4.5\% Asian, and $2 \%$ Other. The average age of participants in this sample was 44.12 years (median $=42, S D=17.03$ ). Regarding education, $13 \%$ did not finish high school, $25 \%$ completed only high school, $21 \%$ attended some college, $20 \%$ received a four-year college degree, and $12 \%$ stated that they completed graduate school. About $40 \%$ report typically voting Democrat, 9\% report voting Independent, $29 \%$ report voting Republican, and $22 \%$ report not voting. Also, unlike study 2, we did not limit this study to YouTube users, but use of the platform was still high. Almost half of the sample reported using it daily, $25 \%$ at least weekly, $9 \%$ at least monthly, $7 \%$ less often than monthly, and $11 \%$ report never using it.

\subsection{Study Design and Procedures}

Study design and hypotheses for studies 2 and 3 were pre-registered prior to data collection. The full preregistered analyses can be found at https://osf.io/h92y5.

Unlike study 1, participants in studies 2 and 3 were not randomized into different video conditions (though 202 participants in Study 3 were not shown any video to serve as a control sample). Instead, participants were shown the same 5-minute video called flat Earth in 5 Minutes produced by ODD TV and posted on the ODD Reality YouTube channel. The video was originally posted in 2017, and, at the time of data collection, had over 1.2 million views. Participants could skip the video after one minute. Study 2 participants were on the page an average of 5.65 minutes (median $=5.2, S D=5.14$ ), and study 3 participants were on the page an average of 4.75 minutes (median $=5.2, S D=3.16$ ).

Afterwards, participants answered questions about their perceptions of the video, about how others might view the video, about potential censorship of flat Earth videos on YouTube, how different the other groups were than themselves (i.e., social distance), and standard demographic questions, which were followed by a fact check statement that provided several ways that the viewer can test the shape of the Earth to see that it is not flat. TurkPrime participants received \$2 upon completion.

\subsection{Measures}

The variables measured in the second study were the same as the first with a few important additions: an index for measuring beliefs that YouTube should censor flat Earth content and ratings of perceived social distance. We describe these in more detail below. Also, we asked the political affiliation question a bit differently, focusing on whom they typically vote for (e.g., the Democratic candidate, the Republican candidate) as opposed to how they categorize themselves. For the full list of measures see the Supplementary File.

\subsubsection{Call for Censorship}

One new component to this survey asked participants about censoring flat Earth videos on YouTube. For these items, participants were shown a series of statements and asked to what extent they agreed or disagreed 
with those statements (strongly disagree $=1$ to strongly agree $=6$ ). See Table 3 for the list of items.

In our preregistration, we stated we would use an averaged index for these items, and we report that analysis in this article. The items have good inter-item reliability and a scree 'acceleration factor' test shows evidence for one factor. However, the non-graphical solutions (e.g., parallel analysis, optimal coordinates analysis) suggest a two-factor solution. This analysis is reported at https://osf.io/h92y5.

\subsubsection{Social Distance}

Also new to this study, we asked participants to rate how similar or dissimilar people from various groups are to themselves (e.g., Eveland et al., 1999). Participants read the following: 'For each of the following identity groups, please tell us whether you feel that the people in this group-whether you belong to the group or not-are a lot like you or not at all like you.' Like for the self-report and the third-person ratings, participants answered this question using a slider scale from 0 to 100 . We reverse coded these variables so that higher values (100) reflected 'Not at all like me' and lower values (0) reflected 'A lot like me.'

Participants were asked about each of the identity groups they rated earlier in the survey, including Republicans (S2: $M=61.15, S D=31.25$; S3: $M=52.65$, $S D=32.97$ ), Democrats (S2: $M=41.24, S D=31.2$; S3: $M=47.85, S D=32.77)$, biblical literalists (S2: $M=71.94$, $S D=32.42$; S3: $M=56.27, S D=33.32$ ), atheists (S2: $M=49.77, S D=32.42 ; \mathrm{S3}: M=64.72, S D=32.58)$, rural dwellers (S2: $M=54.28, S D=29.22$; S3: $M=47.76$, $S D=30.57)$, urban dwellers $(S 2: M=37.92, S D=25.27$; S3: $M=39.10, S D=28.43)$, people who did not go to college (S2: $M=58.34, S D=28.91 ; S 3: M=49.87$, $S D=31.38)$, and people who attended graduate school (S2: $M=41.09, S D=28.53 ; S 3: M=46.67, S D=30.87$ ).
Our data, code, and full pre-registered analysis are available at https://osf.io/h92y5.

\subsection{Results}

\subsubsection{Rating the 'Self' vs. Rating the 'Other'}

Based on study 1 results, our first hypothesis was that participants would rate each of the identity groups as finding the video more convincing then they, themselves, do, except when rating people who attended graduate school. This hypothesis was partially supported in study 2 and fully supported in study 3 (see Table 1). Consistent with study 1 , planned contrasts between ratings for the 'self' and 'others' found that, on average, participants in study 2 expected the following groups to be more convinced by the flat Earth video than themselves: Republicans, biblical literalists, people who live in rural areas, and people who did not go to college. In contrast, study 2 participants, on average, expected people with graduate degrees to be less convinced than they were, whereas study 1 found no significant differences. Moreover, study 2 found no significant differences between 'self' vs. 'other' ratings when rating Democrats and when rating urban dwellers. In contrast, like study 1 , study 3 expected each of the groups to be more convinced by the flat Earth video than themselves, except for those who attended graduate school (see Table 1).

\subsubsection{Predicting TPP Scores}

Our second hypothesis, based on study 1 results, was that religiosity and party affiliation would be two of the strongest predictors of TPP. We also wanted to determine whether social distance was a better predictor of TPP scores than other individual differences variables. As with study 1 , we conducted regression analyses (see Table 4) and Img tests of relative importance (see

Table 3. Censorship items.

\begin{tabular}{|c|c|c|c|c|}
\hline \multirow[b]{2}{*}{ YouTube should... } & \multicolumn{2}{|c|}{$\begin{array}{l}\text { Study } 2 \\
n=404\end{array}$} & \multicolumn{2}{|c|}{$\begin{array}{c}\text { Study } 3 \\
n=1,005\end{array}$} \\
\hline & $M(S D)$ & Median & $M(S D)$ & Median \\
\hline shut down or delete channels that upload flat Earth videos & $1.98(1.22)$ & Disagree & $2.61(1.51)$ & Disagree \\
\hline ban users who upload flat Earth videos & $1.93(1.17)$ & Disagree & $2.58(1.52)$ & Disagree \\
\hline delete videos that argue the Earth is flat & $2.02(1.22)$ & Disagree & $2.68(1.55)$ & Disagree \\
\hline be fined for distributing flat Earth videos & $1.73(1.73)$ & Disagree & $2.37(1.48)$ & Disagree \\
\hline demonetize channels that upload flat Earth videos & $2.76(1.52)$ & $\begin{array}{l}\text { Somewhat } \\
\text { disagree }\end{array}$ & $3.25(1.56)$ & $\begin{array}{c}\text { Somewhat } \\
\text { disagree }\end{array}$ \\
\hline refrain from recommending flat Earth videos to other users & $3.34(1.59)$ & $\begin{array}{c}\text { Somewhat } \\
\text { disagree }\end{array}$ & $3.38(1.51)$ & $\begin{array}{c}\text { Somewhat } \\
\text { disagree }\end{array}$ \\
\hline Cronbach's Alpha & \multicolumn{2}{|c|}{$0.8695 \% \mathrm{Cl}[0.84,0.88]$} & \multicolumn{2}{|c|}{$0.8595 \% \mathrm{Cl}[0.84,0.87]$} \\
\hline Scale Descriptives & \multicolumn{2}{|c|}{$M=2.29, S D=1.00$} & \multicolumn{2}{|c|}{$M=2.81, S D=1.15$} \\
\hline
\end{tabular}

Notes: Participants were shown a series of statements and asked to what extent they agreed or disagreed with those statements on a scale from 1 (strongly disagree) to 6 (strongly agree). 
Table 4. GLM analyses for each identity group.

\begin{tabular}{|c|c|c|c|c|c|c|c|c|c|}
\hline & \multicolumn{9}{|c|}{ Characteristic defining the 'Other' } \\
\hline & $\mathrm{S}$ & Democ & Repub & Urban & Rural & Atheist & $\begin{array}{l}\text { Biblical } \\
\text { Literalists }\end{array}$ & $\begin{array}{c}\text { Grad } \\
\text { School }\end{array}$ & $\begin{array}{l}\text { No } \\
\text { College }\end{array}$ \\
\hline \multirow{2}{*}{$\begin{array}{l}\text { Perceived social } \\
\text { distance }\end{array}$} & 2 & -0.03 & $0.39 * * *$ & 0.02 & $0.26 * * *$ & $0.11^{\top}$ & $0.45 * * *$ & 0.03 & $0.26 * * *$ \\
\hline & 3 & $-0.18^{* * *}$ & 0.04 & $0.10 *$ & $0.13^{* *}$ & $0.13^{* *}$ & $0.13^{* *}$ & -0.01 & $0.13^{* *}$ \\
\hline \multicolumn{10}{|c|}{ Political party (Ref = Democrat) } \\
\hline \multirow[t]{2}{*}{ Republican } & 2 & $11.76^{*}$ & -5.78 & 1.86 & $-12.10 * *$ & 6.15 & $-14.83^{* *}$ & -3.59 & -5.03 \\
\hline & 3 & $8.57^{*}$ & -5.31 & $5.14^{\top}$ & $-5.61^{\top}$ & 5.08 & -4.70 & $5.31 *$ & 0.41 \\
\hline \multirow[t]{2}{*}{ Independent } & 2 & 2.36 & 0.15 & -0.77 & -3.32 & 2.66 & 2.31 & -5.32 & 0.06 \\
\hline & 3 & 7.87 & -5.14 & -2.97 & -2.81 & -6.02 & $-10.94 *$ & 2.61 & -3.58 \\
\hline \multirow[t]{2}{*}{ Other } & 2 & 1.50 & $-12.47^{*}$ & 0.03 & $-9.13^{\top}$ & -7.10 & -6.85 & $-10.29 * *$ & $-10.90 *$ \\
\hline & 3 & 2.44 & -1.41 & -0.01 & -4.77 & 0.34 & -3.01 & 1.29 & -2.15 \\
\hline \multirow[t]{2}{*}{ Religiosity } & 2 & -1.42 & $-6.98 * *$ & -1.44 & $-8.38 * * *$ & -0.84 & $-5.72 *$ & -0.19 & $-8.47 * * *$ \\
\hline & 3 & 0.66 & $-5.14 * * *$ & 1.24 & $-5.21 * * *$ & -2.31 & $-4.76 * *$ & 1.75 & $-4.51 * *$ \\
\hline Conspiracy & 2 & -3.21 & -5.14 & $-6.11 *$ & $-5.89 *$ & -1.85 & $-12.54^{* * *}$ & $-4.59^{\top}$ & $-6.12^{*}$ \\
\hline mentality & 3 & $3.23 *$ & 1.92 & 2.10 & $3.03^{\top}$ & $3.12^{\top}$ & 1.49 & 1.61 & $4.90 * *$ \\
\hline \multirow[t]{2}{*}{ Income } & 2 & -0.23 & -0.72 & -0.12 & -0.73 & -0.48 & -1.07 & -0.35 & -0.03 \\
\hline & 3 & -0.45 & 0.32 & $-0.98^{\top}$ & 0.13 & -0.52 & -0.07 & -0.87 & 0.13 \\
\hline \multirow[t]{2}{*}{ Gender (1 = Male) } & 2 & 0.52 & 2.10 & 0.84 & 0.60 & -3.57 & -0.77 & -3.31 & 0.22 \\
\hline & 3 & -0.08 & -0.06 & -0.08 & -1.20 & -1.62 & -1.35 & -1.20 & -0.53 \\
\hline \multirow[t]{2}{*}{ Age } & 2 & 0.12 & -0.10 & -0.07 & 0.20 & 0.20 & -0.03 & 0.07 & -0.13 \\
\hline & 3 & -0.04 & $0.16^{\top}$ & -0.08 & 0.01 & 0.04 & 0.13 & 0.06 & 0.05 \\
\hline \multicolumn{10}{|l|}{ Area (Ref = Urban) } \\
\hline \multirow[t]{2}{*}{ Rural } & 2 & 1.70 & 2.87 & 3.51 & $9.08^{\top}$ & 0.72 & -0.18 & 1.15 & 0.15 \\
\hline & 3 & $12.61 * * *$ & 4.56 & $5.80^{\top}$ & $9.94 * *$ & $13.28 * *$ & $7.10^{t}$ & $9.58 * *$ & $9.52^{* *}$ \\
\hline \multirow[t]{2}{*}{ Suburban } & 2 & -1.38 & 5.15 & 1.04 & $10.78 * *$ & 2.20 & 6.06 & 2.14 & 0.10 \\
\hline & 3 & $6.75^{*}$ & 3.53 & 1.82 & $8.35^{* *}$ & 3.43 & $6.13^{\top}$ & 0.81 & $8.62 * *$ \\
\hline \multirow[t]{2}{*}{ Education } & 2 & -0.20 & 1.54 & -0.17 & 1.09 & -1.22 & 1.61 & -1.45 & 1.61 \\
\hline & 3 & $2.06 *$ & 1.23 & 1.32 & $2.19 *$ & 1.47 & 1.56 & -0.40 & 1.77 \\
\hline
\end{tabular}

${ }^{\top} p<.10,{ }^{*} p<.05,{ }^{* *} p<.01,{ }^{* * *} p<.001 ;$ S column stands for study, and the numbers 2 and 3 indicate to which study sample the value belongs. Non-standardized regression coefficients are shown.

Figure 3). Supporting our hypotheses, religiosity, party affiliation, and social distance were the strongest predictors of TPP in both studies 2 and 3 (at least for the categories in which study 2 participants perceived the group to be more susceptible to the arguments made in the video than themselves). It is notable that social distance is not always the strongest predictor, and in study 3 , area of residence and religiosity are also strongly predictive of TPP.
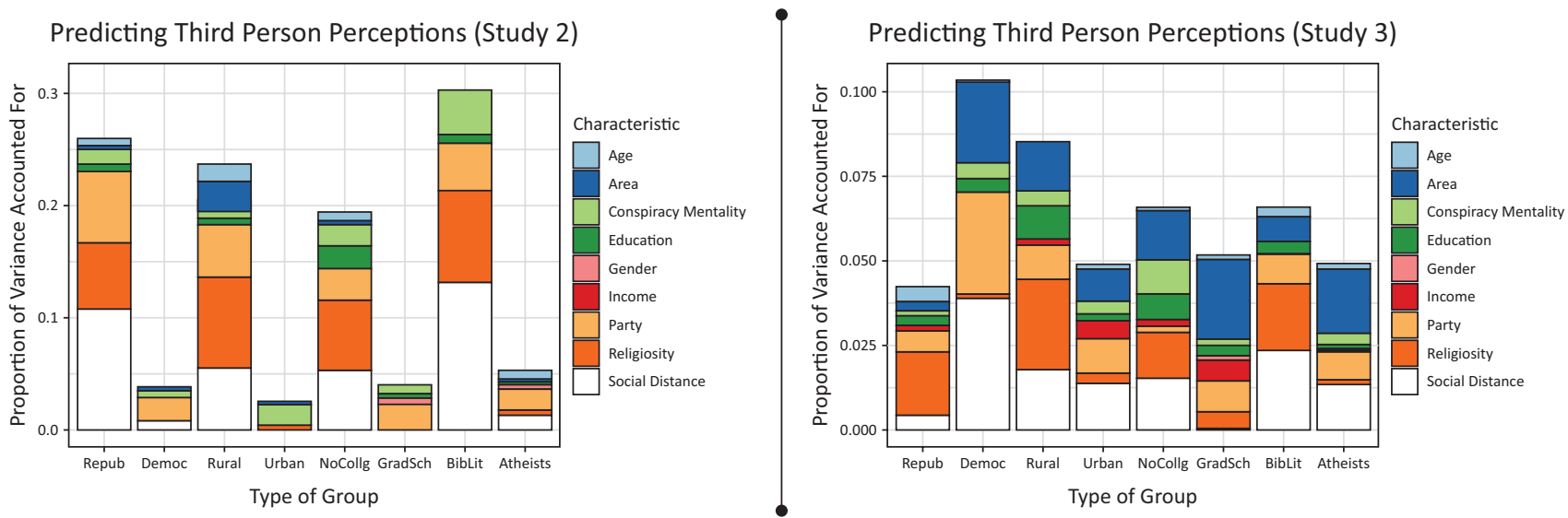

Figure 3. Relative importance of the predictors for studies 2 and 3. Please note the vertical axes differ for the two figures. 
Table 5. Simple correlations between the average censorship score and the TPP scores.

\begin{tabular}{|c|c|c|c|c|}
\hline \multirow[b]{2}{*}{ Group rated } & \multicolumn{2}{|c|}{ Study 2} & \multicolumn{2}{|c|}{ Study 3} \\
\hline & Pearson's $r$ & $95 \% \mathrm{Cl}$ & Pearson's $r$ & $95 \% \mathrm{Cl}$ \\
\hline Democrats & $0.10^{*}$ & {$[0.01,0.20]$} & 0.00 & {$[-0.07,0.07]$} \\
\hline Republicans & $0.26 * * *$ & {$[0.17,0.35]$} & $0.11^{* *}$ & {$[0.04,0.17]$} \\
\hline Urban & $0.17^{* * *}$ & {$[0.08,0.27]$} & 0.05 & {$[-0.02,0.12]$} \\
\hline Rural & $0.23 * * *$ & {$[0.14,0.32]$} & 0.01 & {$[-0.06,0.08]$} \\
\hline Atheists & 0.08 & {$[-0.02,0.18]$} & -0.05 & {$[-0.12,0.02]$} \\
\hline Biblical literalists & $0.22 * * *$ & {$[0.12,0.31]$} & $0.06^{\top}$ & {$[0.00,0.14]$} \\
\hline Graduate school & $0.12^{*}$ & {$[0.02,0.21]$} & $0.10^{* *}$ & {$[0.04,0.17]$} \\
\hline No college & $0.23 * * *$ & {$[0.13,0.32]$} & 0.01 & {$[-0.06,0.08]$} \\
\hline
\end{tabular}

Notes: ${ }^{\top} p<.10,{ }^{*} p<.05,{ }^{* *} p<.01,{ }^{* * *} p<.001$.

\subsubsection{Predicting Censorship of YouTube}

Our third hypothesis was that TPP scores would predict support for censoring YouTube. We tested this hypothesis in two ways. First, we conducted simple correlations. There were positive associations between most of the TPP scores and the censorship scores for study 2, but not for study 3. TPP scores for Republicans and those who attended graduate school were the only two that were significantly correlated with censorship scores for both study 2 and study 3 (see Table 5).

Next, we conducted regression analyses and tests of relative importance, predicting censorship scores from the TPP scores as well as from YouTube use, conspiracy mentality, political party affiliation, religiosity, gender, income, and area of residence. It is worth noting that many of the TPP scores are correlated with one another (see Table 6).

Therefore, to avoid issues with multicollinearity, we used data reduction techniques. A parallel analysis, optimal coordinates analysis, and evaluation of eigenvalues on the study 2 sample suggest that there are two dimensions. We conducted a maximum likelihood factor analysis, extracting two factors with promax (oblique) rotation. TPP scores for Republicans (0.85), rural dwellers (0.97), biblical literalists $(0.73)$, and people who did not attend college (0.76) loaded onto the first factor. In contrast, TPP scores for Democrats (0.95), urban dwellers (0.72), atheists (0.74), and people who attended graduate school (0.69) loaded onto the second factor.

We conducted a confirmatory factor analysis for the study 3 sample using the two-factor solution. The two factor solution was close, but not a good fit for study 3 $\left(\chi^{2}=138.97, \mathrm{p}<.001 ;\right.$ SRMR $=0.037 ; \mathrm{RMSEA}=0.09$, $95 \% \mathrm{Cl}[0.078,0.107] ; \mathrm{CFI}=0.963)$. Supplementary analyses suggest a one-factor solution would be more appropriate. Therefore, when analyzing study 3 data, we used an averaged index of the TPP scores. That a two factor solution was appropriate for study 2 but not study 3 is understandable given the differences in the samples: MTurkers, who lean more liberal and less religious than a nationally representative population, may be more likely

Table 6. Pearson correlations among TPP scores for study 2 and study 3.

\begin{tabular}{|c|c|c|c|c|c|c|c|c|c|}
\hline & Study & DEM & REP & URB & RRL & ATH & $\mathrm{BLT}$ & GRD & NC \\
\hline \multirow[t]{2}{*}{ Democrat (DEM) } & 2 & 10 & $0.32 * * *$ & $0.68 * * *$ & $0.31 * * *$ & $0.62 * * *$ & $0.40 * * *$ & $0.62 * * *$ & $0.45^{* * *}$ \\
\hline & 3 & 1.00 & & & & & & & \\
\hline \multirow[t]{2}{*}{ Republican (REP) } & 2 & & 100 & $0.47 * * *$ & $0.75 * * *$ & $0.35^{* * *}$ & $0.68 * * *$ & $0.47 * * *$ & $0.67 * * *$ \\
\hline & 3 & $0.35^{* * *}$ & 1.00 & & & & & & \\
\hline \multirow[t]{2}{*}{ Urban (URB) } & 2 & & & 100 & $0.45^{* * *}$ & $0.54 * * *$ & $0.45^{* * *}$ & $0.61 * * *$ & $0.53 * * *$ \\
\hline & 3 & $0.64 * * *$ & $0.47 * * *$ & 1.00 & & & & & \\
\hline \multirow[t]{2}{*}{ Rural (RRL) } & 2 & & & & 100 & $0.29 * * *$ & $0.67^{* * *}$ & $0.38 * * *$ & $0.75 * * *$ \\
\hline & 3 & $0.44 * * *$ & $0.65 * * *$ & $0.48 * * *$ & 1.00 & & & & \\
\hline \multirow[t]{2}{*}{ Atheist (ATH) } & 2 & & & & & & $0.23 * * *$ & $0.55^{* * *}$ & $0.39 * * *$ \\
\hline & 3 & $0.59 * * *$ & $0.41 * * *$ & $0.54 * * *$ & $0.46 * * *$ & 1.00 & & & \\
\hline \multirow[t]{2}{*}{ Bibl lit (BLT) } & 2 & & & & & & & $0.41 * * *$ & $0.64 * * *$ \\
\hline & 3 & $0.40 * * *$ & $0.64 * * *$ & $0.47^{* * *}$ & $0.61 * * *$ & $0.38 * * *$ & 1.00 & & \\
\hline \multirow[t]{2}{*}{ Graduate sch (GRD) } & 2 & & & & & & & 10 & $0.37^{* * *}$ \\
\hline & 3 & $0.56 * * *$ & $0.47^{* * *}$ & $0.60 * * *$ & $0.37 * * *$ & $0.42^{* * *}$ & $0.40 * * *$ & 1.00 & \\
\hline \multirow[t]{2}{*}{ No college (NC) } & 2 & & & & & & & & \multirow{2}{*}{1.00} \\
\hline & 3 & $0.50 * * *$ & $0.57 * * *$ & $0.51 * * *$ & $0.68 * * *$ & $0.56 * * *$ & $0.59 * * *$ & $0.40 * * *$ & \\
\hline
\end{tabular}

Notes: ${ }^{\top} p<.10,{ }^{*} p<.05,{ }^{* *} p<.01,{ }^{* * *} p<.001$. 
Table 7. Predicting censorship scores. Non-standardized regression coefficients are shown.

\begin{tabular}{|c|c|c|c|c|c|c|}
\hline & \multicolumn{3}{|c|}{ Study 2} & \multicolumn{3}{|c|}{ Study 3} \\
\hline & $b$ & $F$ & Img & $b$ & $F$ & Img \\
\hline YouTube Use & -0.10 & 0.85 & $0.23 \%$ & -0.06 & 2.50 & $0.41 \%$ \\
\hline TPP-F1 & $0.01 *$ & $5.11^{*}$ & $3.85 \%$ & 0.00 & 1.22 & $0.17 \%$ \\
\hline $\mathrm{TPP}-\mathrm{F} 2$ & 0.00 & 1.15 & $1.12 \%$ & NA & NA & NA \\
\hline Party (ref = Democ) & & $4.76^{* *}$ & $4.79 \%$ & & 0.51 & $0.24 \%$ \\
\hline Republican & $-0.50 * * *$ & & & -0.02 & & \\
\hline Independent & $-0.30^{\top}$ & & & -0.19 & & \\
\hline Other & $-0.32 *$ & & & 0.05 & & \\
\hline Religiosity & 0.02 & 0.06 & $0.61 \%$ & 0.08 & 2.25 & $0.65 \%$ \\
\hline Conspiracy mentality & -0.08 & 0.70 & $0.54 \%$ & $-0.12 *$ & $5.46^{*}$ & $0.43 \%$ \\
\hline Income & 0.01 & 0.09 & $0.05 \%$ & $-0.05^{*}$ & $4.10^{*}$ & $0.03 \%$ \\
\hline Gender & -0.01 & 0.01 & $0.05 \%$ & -0.02 & 0.03 & $0.40 \%$ \\
\hline Area (ref = Urban) & & 0.04 & $0.10 \%$ & & 1.32 & $0.40 \%$ \\
\hline Rural & -0.03 & & & 0.06 & & \\
\hline Suburban & -0.03 & & & -0.13 & & \\
\hline Education & 0.03 & 0.58 & $0.44 \%$ & $0.07^{*}$ & $3.90 *$ & $0.24 \%$ \\
\hline
\end{tabular}

Notes: ${ }^{\top} p<.10,{ }^{*} p<.05,{ }^{* *} p<.01,{ }^{* * *} p<.001$.

to see stronger divides than a more representative sample, grouping together Democrats, urban dwellers, atheists, and people who attended graduate school in one bin and Republicans, rural dwellers, biblical literalists, and people who did not go to college in another.

In study 2, we found partial support for our hypothesis that TPP scores predict censorship: Specifically, TPP scores for the dimension that captured perceptions of Republicans, biblical literalists, rural dwellers, and people who did not go to college. It is worth noting, though, that political party was a stronger predictor of censorship scores than TPP scores; participants political party affiliation explained approximately $4.76 \%$ of the response variance, whereas TPP scores (factor 1) explained approximately $3.85 \%$ of the response variance. Moreover, in study 3 , however, we did not find support for our hypothesis. TPP scores did not significantly predict censorship and explained approximately only $0.24 \%$ of the response variance (see Table 7).

\section{Discussion}

This article presents three studies examining two research aims. Our first aim was to determine which identity groups people believe are more susceptible than themselves to flat Earth videos, and whether these TPP are conditional on participants' own characteristics. For studies 1 and 2, people who believe the Bible should be interpreted literally (i.e., biblical literalists) were viewed as the most susceptible to flat Earth arguments on YouTube. This is unsurprising given the historical connection of flat Earth and its associated beliefs (e.g., geocentricism) to biblical literalism as well as the many appeals by the flat Earth community to the Bible as a source of evidence. In study 3, people without college degrees were seen as being as susceptible as biblical literalists.
Supporting prior TPP literature, our studies find a 'self'-'other' bias in which participants generally rated the 'other' groups as being more susceptible to flat Earth videos than themselves, and this is predicted by perceived social distance (supporting the social distance corollary; cf. Eveland et al., 1999). However, it is not only social distance that predicts TPP. Participants' own religiosity and political party are also strongly predictive, even when accounting for the other factors.

Our second aim was to determine the extent to which these TPP predict support for censorship of YouTube. Before discussing these results, a few points are important to note. First, support for censorship was generally low among the YouTube users who composed our sample for study 2. We thought it was possible that support for censorship would increase in a more representative sample not restricted to YouTube users (but controlling for YouTube use). However, this also was not the case. Although support for censorship was slightly higher for study 3 than for study 2 , the distribution of scores were still positively skewed with a floor effect. Second, there seemed to be an effect of seeing a flat Earth video on support for censorship in the unexpected direction. In study 3 , we included a sub sample of participants who did not see any video but were still asked the censorship questions. Participants who did not see the flat Earth video $(M=3.01$ of $6, S D=1.05)$ were more open to censoring flat Earth videos than participants who had seen the video $(M=2.76, S D=1.17), t(338.30)=2.99$, $\mathrm{p}<.003$.

We only found partial support for the hypothesis that TPP scores predict the desire for censorship. In fact, there were differences between our two samples (study 2 and study 3 ). In study 2 , the TPP scores for most of the identity groups were correlated with censorship scores, and one of the TPP factors (i.e., the one on which Republicans, 
biblical literalists, rural dwellers, and people who did not go to college loaded) predicted desire for censorship. For study 3, however, only two of the TPP scores-the ones for Republicans and people who attended graduate school-predicted censorship scores, and the TPP average score did not predict desire for censorship when accounting for other factors.

These results are not entirely inconsistent with prior work on TPE. On one hand, TPP have been shown to predict support for censorship for several socially undesirable messages, such as violence and sexual content on television (Gunther \& Hwa, 1996; Rojas et al., 1996), advertising for cigarettes, alcohol, and gambling (Shah, Faber, \& Youn, 1999), rap music (McLeod, Eveland, \& Nathanson, 1997), and for the media in general (Rojas et al., 1996). On the other hand, several other studies failed to find associations between TPP and support for censorship. These studies included support for censoring the O. J. Simpson trial (Salwen \& Driscoll, 1997) and Holocaust-denial material (Price, Tewksbury, \& Huang, 1998), and for the regulation of political communications (Rucinski \& Salmon, 1990). Thus, there does not seem to be a clear relationship between TPP and censorship attitudes, and message type may have a moderating effect.

\section{Conclusions}

Because YouTube recently announced modifications to its recommendation algorithms and specifically mentioned flat Earth in its announcement (YouTube, 2019), it is evident that the management at YouTube is concerned about the influence of these videos on the public. Undoubtedly, YouTube was facing public pressure to take some action as a result of recent issues, such as articles blaming YouTube's algorithms for the rise in flat Earthers and promotion of other conspiracies, like QAnon (Coaston, 2018). Presumably, those who support regulation of such content, as well as YouTube's upper management who implemented these regulations, hold strong TPP, and they may have overestimated the effects these videos would have on others. Though our research only partially supports the theory that the general public would support censoring flat Earth videos on YouTube based on their own TPP, such perceptions may have played a significant role in these executives' decision making.

\section{Acknowledgments}

The authors would like to thank the members of the Science Communication and Cognition Lab and the faculty and staff of the College of Media and Communication at Texas Tech University for their help and support.

\section{Conflict of Interests}

The authors declare no conflict of interests.

\section{Supplementary Material}

Supplementary material for this article is available online in the format provided by the authors (unedited).

\section{References}

Binder, M. (2019, January 25). YouTube promises to stop recommending conspiracy theory videos. Mashable. Retrieved from https://mashable.com/article/ YouTube-to-stop-recommending-conspiracytheories/\#lwrefcc4ouqw

Bruder, M., Haffke, P., Neave, N., Nouripanah, N., \& Imhoff, R. (2013). Measuring individual differences in generic beliefs in conspiracy theories across cultures: Conspiracy mentality questionnaire. Frontiers in Psychology, 4. http://doi.org/10.3389/fpsyg.2013. 00225

Burnham, M. J., Le, Y. K., \& Piedmont, R. L. (2018). Who is Mturk? Personal characteristics and sample consistency of these online workers. Mental Health, Religion \& Culture, 21(9/10), 934-944. https://doi.org/ 10.1080/13674676.2018.1486394

Coaston, J. (2018, December 14). YouTube's conspiracy theory crisis, explained. Vox. Retrieved from https:// www.vox.com/technology/2018/12/12/18136132/ google-YouTube-congress-conspiracy-theories

Cohen, J., Mutz, D., Price, V., \& Gunther, A. (1988). Perceived impact of defamation: An experiment on third-person effects. Public Opinion Quarterly, 52(2), 161-173. https://doi.org/10.1086/269092

David, P., Morrison, G., Johnson, M. A., \& Ross, F. (2002). Body image, race, and fashion models: Social distance and social identification in third-person effects. Communication Research, 29(3), 270-294. https:// doi.org/10.1177/0093650202029003003

Davison, W. P. (1983). The third-person effect in communication. Public Opinion Quarterly, 47(1), 1-15. https://doi.org/10.1086/268763

Douglas, K. M., \& Sutton, R. M. (2008). The hidden impact of conspiracy theories: Perceived and actual influence of theories surrounding the death of Princess Diana. The Journal of Social Psychology, 148(2), 210-222. https://doi.org/10.3200/SOCP.148. 2.210-222

Dubay, E. (2018, August 18). 200 Proofs Earth is not a spinning ball. [Video file]. Retrieved from https:// www.youtube.com/watch?v=x0EGB_o9TZM

Eveland, W. P., Nathanson, A. I., Detenber, B. H., \& McLeod, D. M. (1999). Rethinking the social distance corollary: Perceived likelihood of exposure and third-person perception. Communication Research, 26(3), 275-302. http://doi.org/10.1177/ 009365099026003001

Gardikiotis, A. (2008). Group distinctiveness, political identification, and the third-person effect: Perceptions of a political campaign in the 2004 Greek national election. Media Psychology, 11(3), 331-353. 
https://doi.org/10.1080/15213260801994212

Grömping, U. (2006). Relative importance for linear regression in R: The package relaimpo. Journal of Statistical Software, 17(1), 1-27.

Gunther, A. (1991). What we think others think: Cause and consequence in the third-person effect. Communication Research, 18(3), 355-372. http://doi.org/ 10.1177/009365091018003004

Gunther, A. (1995). Overrating the X-rating: The third-person perception and support for censorship of pornography. Journal of Communication, 45(1), 27-38. https://doi.org/10.1111/j.1460-2466.1995. tb00712.x

Gunther, A. C., \& Hwa, A. P. (1996). Public perceptions of television influence and opinions about censorship in Singapore. International Journal of Public Opinion Research, 8(3), 248-265. http://doi.org/10.1093/ijpor/ 8.3.248

Hoffner, C., \& Buchanan, M. (2002). Parents' responses to television violence: The third-person perception, parental mediation, and support for censorship. Media Psychology, 4(3), 231-252. http://doi.org/ 10.1207/S1532785XMEP0403_02

Huh, J., Delorme, D. E., \& Reid, L. N. (2004). The thirdperson effect and its influence on behavioral outcomes in a product advertising context: The case of direct-to-consumer prescription drug advertising. Communication Research, 31(5), 568-599. https:// doi.org/10.1177/0093650204267934

Innes, J. M., \& Zeitz, H. (1988). The public's view of the impact of the mass media: A test of the 'third person' effect. European Journal of Social Psychology, 18(5), 457-463. https://doi.org/10.1002/ejsp.2420180507

Jang, S. M., \& Kim, J. K. (2018). Third person effects of fake news: Fake news regulation and media literacy interventions. Computers in Human Behavior, 80, 295-302. https://doi.org/10.1016/j.chb.2017.11. 034

Landrum, A. R., \& Olshansky, A. (2019). 2017 flat Earth conference interviews. Retrieved from https://doi. org/10.17605/OSF.IO/CW7RE

Landrum, A. R., Olshansky, A., \& Richards, O. (2019). Differential susceptibility to misleading flat Earth arguments on YouTube. Media Psychology. http://doi. org/10.1080/15213269.2019.1669461

Lindeman, R. H., Merenda, P. F., \& Gold, R. Z. (1980). Introduction to bivariate and multivariate analysis. Glenview, IL: Scott Foresman.

Lo, V. H., \& Wei, R. (2002). Third-person effect, gender, and pornography on the Internet. Journal of Broadcasting \& Electronic Media, 46(1), 13-33. https://doi. org/10.1207/s15506878jobem4601_2

McLeod, D. M., Eveland, W. P., Jr., \& Nathanson, A. I. (1997). Support for censorship of violent and misogynic rap lyrics: An analysis of the third-person effect. Communication Research, 24(2), 153-174. http://doi. org/10.1177/009365097024002003

Meirick, P. C. (2004). Topic-relevant reference groups and dimensions of distance: Political advertising and first-and third-person effects. Communication Research, 31(2), 234-255. https://doi.org/10.1177/ 0093650203261514

Paek, H. J. (2009). Differential effects of different peers: Further evidence of the peer proximity thesis in perceived peer influence on college students' smoking. Journal of Communication, 59(3), 434-455. https:// doi.org/10.1111/j.1460-2466.2009.01423.x

Paolillo, J. C. (2018). The flat Earth phenomenon on YouTube. First Monday, 23(12). https://doi.org/ 10.5210/fm.v23i12.8251

Perloff, R. M. (1993). Third-person effect research 1983-1992: A review and synthesis. International Journal of Public Opinion Research, 5(2), 167-184. http://doi.org/10.1093/ijpor/5.2.167

Perloff, R. M. (2009). Mass media, social perception, and the third-person effect. In J. Bryant \& M. B. Oliver (Eds.), Media effects: Advances in theory and research (3rd ed., pp. 252-268). New York, NY: Routledge.

Price, V., Tewksbury, D., \& Huang, L. N. (1998). Thirdperson effects on publication of a Holocaustdenial advertisement. Journal of Communication, 48(2), 3-26. http://doi.org/10.1111/j.1460-2466. 1998.tb02745.x

Rojas, H., Shah, D. V., \& Faber, R. J. (1996). For the good of others: Censorship and the third-person effect. International Journal of Public Opinion Research, 8(2), 163-186. https://doi.org/10.1093/ijpor/8.2.163

Rucinski, D., \& Salmon, C. T. (1990). The 'other' as the vulnerable voter: A study of the third-person effect in the 1988 US presidential campaign. International Journal of Public Opinion Research, 2(4), 345-368. http://doi.org/10.1093/ijpor/2.4.345

Salwen, M. B. (1998). Perceptions of media influence and support for censorship: The third-person effect in the 1996 presidential election. Communication Research, 25(3), 259-285. http://doi.org/10.1177/ 009365098025003001

Salwen, M. B., \& Driscoll, P. D. (1997). Consequences of third-person perception in support of press restrictions in the OJ Simpson trial. Journal of Communication, 47(2), 60-78. http://doi.org/10.1111/j.14602466.1997.tb02706.x

Scott, S. (2019, May 14). YouTube's algorithm is spreading a series of unfortunate far-right events. The Drum. Retrieved from https://www.thedrum.com/opinion/ 2019/05/14/YouTube-s-algorithm-spreadingseries-unfortunate-far-right-events?fbclid= iwar1nrlfcf5p-fx0y9q9k7sv8tilaiz_08e97r1mv266mqlyd25kec4pkea

Shah, D. V., Faber, R. J., \& Youn, S. (1999). Susceptibility and severity: Perceptual dimensions underlying the third-person effect. Communication Research, 26(2), 240-267. http://doi.org/10.1177/ 009365099026002006

Shen, L., \& Huggins, C. (2013). Testing the model of in- 
fluence of presumed influence in a boundary condition: The impact of question order. Human Communication Research, 39(4), 470-491. https://doi.org/ 10.1111/hcre.12013

Wei, R., Chia, S. C., \& Lo, V. H. (2011). Third-person effect and hostile media perception influences on voter attitudes toward polls in the 2008 US presidential election. International Journal of Public Opinion Research, 23(2), 169-190. https://doi.org/10.1093/ ijpor/edq044

YouGov. (2018a). Most flat Earthers consider themselves very religious. YouGov. Retrieved from https://today.yougov.com/topics/philosophy/ articles-reports/2018/04/02/most-flat-earthersconsider-themselves-religious
YouGov. (2018b). Americans think ghosts are more likely than aliens on Earth. YouGov. Retrieved from https://today.yougov.com/topics/philosophy/ articles-reports/2018/10/31/americans-thinkghosts-are-more-likely-aliens-eart

YouTube. (2019, January 25). Continuing our work to improve recommendations on YouTube. YouTube Blog. Retrieved from https://YouTube.googleblog.com/ 2019/01/continuing-our-work-to-improve.html

Zhao, X., \& Cai, X. (2008). From self-enhancement to supporting censorship: The third-person effect process in the case of Internet pornography. Mass Communication and Society, 11(4), 437-462. https://doi.org/ $10.1080 / 15205430802071258$

\section{About the Authors}

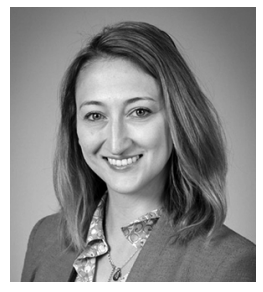

Asheley R. Landrum is an Assistant Professor in the College of Media and Communication at Texas Tech University and a media psychologist. Her research investigates how values and world-views influence people's selection and processing of science media and how these phenomena develop from childhood into adulthood. In addition to her work on the flat Earth movement, she is the Co-Principal Investigator on an NSF-funded project aiming to better understand how to help science media professionals engage their missing audiences.

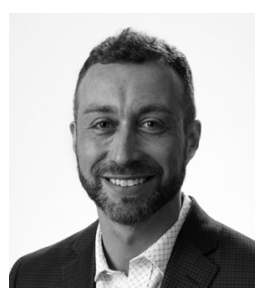

Alex Olshansky is a PhD Student in the college of Media and Communication at Texas Tech University. He holds a BA degree in Finance from the University of Texas at Dallas and a MA degree in Mass Communication from Texas Tech University. His research focuses on science communication via social media and investigates how the transmission of misinformation, cultural values, and world-views influence people's perceptions of science. 